\title{
Perivascular leukocyte clusters are essential for efficient activation of effector $T$ cells in the skin.
}

\section{$\operatorname{AUTHOR}(\mathrm{S})$ :}

Natsuaki, Yohei; Egawa, Gyohei; Nakamizo, Satoshi; Ono, Sachiko; Hanakawa, Sho; Okada, Takaharu; Kusuba, Nobuhiro; ... Guttman-Yassky, Emma; Miyachi, Yoshiki; Kabashima, Kenji

\section{CITATION:}

Natsuaki, Yohei ... [et al]. Perivascular leukocyte clusters are essential for efficient activation of effector T cells in the skin.. Nature immunology 2014, 15: 1064-1069

\section{ISSUE DATE:}

2014-09-21

URL:

http://hdl.handle.net/2433/189891

\section{RIGHT:}

(c) 2014 Nature America, Inc.; 許諾条件により本文は2015-03-22に公開.; This is not the published version. Please cite only the published version.; この論文は出版社版でありません。引用の際には出版社版を ご確認ご利用ください。 
Natsuaki et al

1 Perivascular leukocyte clusters are essential for efficient effector $\mathbf{T}$ cell activation in the skin

3

Yohei Natsuaki ${ }^{1,13,15}$, Gyohei Egawa ${ }^{1,15}$, Satoshi Nakamizo ${ }^{1}$, Sachiko Ono ${ }^{1}$, Sho Hanakawa ${ }^{1}$, Takaharu Okada ${ }^{2}$, Nobuhiro Kusuba ${ }^{1}$, Atsushi Otsuka ${ }^{1}$, Akihiko Kitoh ${ }^{1}$, Tetsuya Honda ${ }^{1}$, Saeko Nakajima ${ }^{1}$, Soken Tsuchiya ${ }^{3}$, Yukihiko Sugimoto ${ }^{3}$, Ken J. Ishii ${ }^{4,5}$, Hiroko Tsutsui ${ }^{6}$, Hideo Yagita ${ }^{7}$, Yoichiro Iwakura ${ }^{8,9}$, Masato Kubo ${ }^{10,11}$, Lai guan $\mathrm{Ng}^{12}$, Takashi Hashimoto ${ }^{13}$, Judilyn Fuentes ${ }^{14}$, Emma Guttman-Yassky ${ }^{14}$, Yoshiki Miyachi ${ }^{1}$, and Kenji Kabashima ${ }^{1}$ 9

${ }^{1}$ Department of Dermatology, Kyoto University Graduate School of Medicine, Kyoto, Japan.

${ }^{2}$ Research Unit for Immunodynamics, RIKEN Research Center for Allergy and Immunology, Kanagawa, Japan.

${ }^{3}$ Department of Pharmaceutical Biochemistry, Graduate School of Pharmaceutical Sciences, Kumamoto University, Kumamoto, Japan.

${ }^{4}$ Laboratory of Adjuvant Innovation, National Institute of Biomedical Innovation, Osaka, Japan.

${ }^{5}$ Laboratory of Vaccine Science, WPI Immunology Frontier Research Center (iFReC), Osaka University, Osaka, Japan.

${ }^{6}$ Departments of Microbiology, Hyogo College of Medicine, Hyogo, Japan.

${ }^{7}$ Department of Immunology, Juntendo University School of Medicine, Tokyo, Japan.

${ }^{8}$ Research Institute for Biomedical Sciences, Tokyo University of Science, Chiba, Japan

${ }^{9}$ Medical Mycology Research Center, Chiba University, Chiba, Japan

${ }^{10}$ Laboratory for Cytokine Regulation, RIKEN center for Integrative Medical Science (IMS), Kanagawa, Japan.

${ }^{11}$ Division of Molecular Pathology, Research Institute for Biomedical Science, Tokyo University of Science, Chiba, Japan

12 Singapore Immunology Network (SIgN), A*STAR (Agency for Science, Technology and Research), Biopolis, Singapore

${ }^{13}$ Department of Dermatology, Kurume University School of Medicine, Fukuoka, Japan.

${ }^{14}$ Department of Dermatology, Icahn School of Medicine at Mount Sinai School Medical Center, New York, NY.

${ }^{15}$ These authors contributed equally to this work. 
Natsuaki et al

35 Correspondence to Kenji Kabashima, MD, PhD

36 Department of Dermatology, Kyoto University Graduate School of Medicine

3754 Shogoin-Kawahara, Kyoto 606-8507, Japan

38 Phone: +81-75-751-3605; Fax: +81-75-761-3002

39 E-mail: kaba@kuhp.kyoto-u.ac.jp

40 
41 It remains largely unclear how antigen-presenting cells encounter effector or memory T cells

42 efficiently in the periphery. Here we used a murine contact hypersensitivity model and

43 showed that upon epicutaneous antigen challenge, dendritic cells (DCs) formed clusters with

44 effector T cells in dermal perivascular areas to promote in situ proliferation and activation of

45 skin T cells in an antigen- and integrin LFA-1-dependent manner. We found that DCs

46 accumulated in perivascular areas and DC clustering was abrogated by macrophage-depletion.

47 Interleukin $1 \alpha(\mathrm{IL}-1 \alpha)$ treatment induced the production of the chemokine CXCL2 from

48 dermal macrophages, and DC clustering was suppressed by blockade of either IL-1 receptor

49 (IL-1R) or CXCR2, the receptor for CXCL2. These findings suggest that dermal leukocyte

50 cluster is an essential structure for elicitation of the acquired cutaneous immunity. 
Boundary tissues, including the skin, are continually exposed to foreign antigens, which must be monitored and possibly eliminated. Upon foreign antigen exposure, skin dendritic cells (DCs), including epidermal Langerhans cells (LCs), capture the antigens and migrate to draining lymph nodes (LNs) where antigen presentation to naïve T cells occurs mainly in the T cell zone. In this location naïve T cells accumulation in the vicinity of DCs is mediated by CCR7 signaling ${ }^{1}$. The T cell zone in the draining LNs facilitates the efficient encounter of antigen-bearing DCs with antigen-specific naïve T cells.

As opposed to LNs, the majority of skin T cells, including infiltrating skin T cells and skin resident $\mathrm{T}$ cells, have an effector-memory phenotype ${ }^{2}$. In addition, antigen presentation to skin T cells by antigen-presenting cells (APCs) is the crucial step in elicitation of acquired skin immune responses, such as contact dermatitis. Therefore, we hypothesize that antigen-presentation in the skin should be substantially different from that in LNs. ,Previous studies using murine contact hypersensitivity (CHS), as a model of human contact dermatitis, have revealed that dermal DCs (dDCs), but not epidermal LCs, have a pivotal role in the transport and presentation of antigen to the $\mathrm{LNs}^{3}$. In the skin, however, it remains unclear which subset of APCs presents antigens to skin T cells, and how skin T cells efficiently encounter APCs. In addition, dermal macrophages are key modulators in CHS response ${ }^{4}$, but the precise mechanisms by which macrophages are involved in antigen recognition in the skin have not yet been clarified. These unsolved questions prompted us to focus where skin T cells recognize antigens and how skin T cells are activated in the elicitation phase of acquired cutaneous immune responses, such as CHS.

When keratinocytes encounter foreign antigens, they immediately produce various pro-inflammatory mediators such as interleukin 1(IL-1) and tumor necrosis factor (TNF) in an antigen-nonspecific manner ${ }^{5,6}$. IL-1 family proteins are considered important modulators in CHS responses, because hapten-specific T cell activation was shown to be impaired in IL-1 $\alpha$ and IL-1 $\beta$-deficient mice, but not in TNF-deficient mice ${ }^{7}$. IL-1 $\alpha$ and IL-1 $\beta$ are agonistic ligands of the IL-1 receptor (IL-1R). While IL-1 $\alpha$ is stored in keratinocytes and secreted upon exposure to nonspecific stimuli, IL-1 $\beta$ is produced mainly by epidermal LCs and dermal mast cells in an inflammasome-dependent manner via NALP3 and caspase 1/11 activation. Because these pro-inflammatory mediators are crucial in the initiation of acquired immune responses such as CHS, it is of great interest to understand how IL-1 modulates antigen recognition by skin $\mathrm{T}$ cells.

\section{Using a murine CHS model, here we examined how DCs and effector T cells encounter}


each other efficiently in the skin. We found that upon encounter with antigenic stimuli dDCs formed clusters in which effector $\mathrm{T}$ cells were activated and proliferated in an antigen-dependent manner. These DC-T cell clusters were initiated by skin macrophages via IL-1R signaling and were essential for the establishment of cutaneous acquired immune responses.

\section{RESULTS}

\section{DC-T cell clusters are formed at antigen-challenged sites}

To explore immune cell accumulation in the skin, we examined the clinical and histological features of elicitation of human allergic contact dermatitis. Allergic contact dermatitis is the most common of eczematous skin diseases, affecting 15-20\% of the general population worldwide $^{8}$, and is mediated by T cells. Although antigens may be applied relatively evenly over the surface of skin, clinical manifestations commonly include discretely distributed small vesicles (Fig. 1a), suggesting an uneven occurrence of intense inflammation. Histological examination of allergic contact dermatitis showed spongiosis, intercellular edema in the epidermis and co-localization of perivascular infiltrates of $\mathrm{CD}^{+} \mathrm{T}$ cells and spotty accumulation of CD11c ${ }^{+}$DCs in the dermis, especially beneath the vesicles (Fig. 1b). These findings led us to hypothesize that focal accumulation of T cells and DCs in the dermis may contribute to vesicle formation in early eczema.

To characterize the DC-T cell clusters in elicitation reactions, we obtained time-lapse images in a murine model of CHS using two-photon microscopy. T cells were isolated from the draining LNs of 2, 4-dinitrofluorobenzene (DNFB)-sensitized mice, labeled and transferred into CD11c-yellow fluorescent protein (YFP) mice. In the steady state, $\mathrm{YFP}^{+}$ dDCs distributed diffusely (Fig. 1c), representing nondirected movement in a random fashion, as reported previously (Supplementary Fig. 1). After topical challenge with DNFB, YFP ${ }^{+}$ dDCs transiently increased their velocities and formed clusters in the dermis, with the clusters becoming larger and more evident after $24 \mathrm{~h}$ (Fig. 1c and Supplementary Movie 1). At the same time, transferred T cells accumulated in the DC clusters and interacted with $\mathrm{YFP}^{+} \mathrm{DCs}$ for several hours (Fig. 1d and Supplementary Movie 2). Thus, the accumulation of DCs and T cells in the dermis is observed in mice during CHS responses. We observed that the intercellular spaces between keratinocytes overlying the DC-T cell clusters in the dermis were enlarged (Fig. 1e), replicating observations in human allergic contact dermatitis (Fig. 1b). 
We next sought to determine which of the two major DC populations in skin, epidermal LCs or dDCs, were essential for the elicitation of CHS. To deplete all cutaneous DC subsets, Langerin-diphtheria toxin receptor (DTR) mice were transferred with bone marrow (BM) cells from CD11c-DTR mice. To selectively deplete LCs or dDCs, Langerin-DTR or C57BL/6 mice were transferred with BM cells from C57BL/6 mice or CD11c-DTR mice, respectively (Supplementary Fig. 2a, b). We injected diphtheria toxin (DT) for depletion of each DC subset before elicitation and found that ear swelling and inflammatory histological findings were significantly attenuated in the absence of dDCs, but not in the absence of LCs (Fig. 1f and Supplementary Fig. 2c). In addition, interferon (IFN)- $\gamma$ production in skin T cells was strongly suppressed in dDC-depleted mice (Fig. 19). These results suggest that dDCs, and not epidermal LCs, are essential for T cell activation and the elicitation of CHS responses.

\section{Skin effector $\mathbf{T}$ cells proliferate in situ in an antigen-dependent manner}

To evaluate the impact of DC-T cell clusters in the dermis, we determined whether T cells had acquired the ability to proliferate via DC-T cell accumulation in the dermis. $\mathrm{CD}^{+}$or $\mathrm{CD}^{+} \mathrm{T}$ cells purified from the draining LNs of DNFB-sensitized mice were labeled with CellTrace $^{\mathrm{TM}}$ Violet and transferred into naïve mice. Twenty-four hours after DNFB application, we collected the skin to evaluate $\mathrm{T}$ cell proliferation by dilution of fluorescent intensity. The majority of infiltrating T cells were CD44 ${ }^{+}$CD62L- effector T cells (Supplementary Fig. 2d). Among the infiltrating T cells, CD8 ${ }^{+} \mathrm{T}$ cells proliferated actively, whereas the $\mathrm{CD}^{+} \mathrm{T}$ cells showed low proliferative potency (Fig. 2a). This T cell proliferation was antigen-dependent, because 2,4,6-trinitrochlorobenzene (TNCB)-sensitized T cells exhibited low proliferative activities in response to DNFB application (Fig. 2a). In line with this finding, the DC-T cell conjugation time was prolonged in the presence of cognate antigens (Fig. 2b), and the T cells interacting with DCs within DC-T cell clusters proliferated (Fig. 2c and Supplementary Movie 3). Our findings indicate that skin effector T cells conjugate with DCs and proliferate in situ in an antigen-dependent manner.

\section{CD8 $^{+} \mathbf{T}$ cell activation in DC-T cell clusters is LFA-1 dependent}

A sustained interaction between DCs and naïve T cells, which is known as an immunological synapse, is maintained by cell adhesion molecules ${ }^{9}$. Particularly, the integrin LFA-1 on T cells binds to cell surface glycoproteins, such as intercellular adhesion molecule-1 (ICAM-1), 
on APCs, which is essential for naïve T cell proliferation and activation during antigen recognition in the LNs. To examine whether LFA-1-ICAM-1 interactions are required for effector T cell activation in DC-T cell clusters in the skin, an anti-LFA-1 neutralizing antibody, KBA, was intravenously injected $14 \mathrm{~h}$ after elicitation with DNFB in CHS. KBA administration reduced $\mathrm{T}$ cells accumulation in the dermis (Fig. 3a). The velocity of $\mathrm{T}$ cells in the cluster was $0.65 \pm 0.29 \mu \mathrm{m} / \mathrm{min} 14 \mathrm{~h}$ after DNFB challenge and increased up to 3-fold $(1.64 \pm 1.54 \mu \mathrm{m} / \mathrm{min})$ at $8 \mathrm{~h}$ after treatment with KBA, while it was not affected by treatment with an isotype-matched control IgG (Fig. 3b). At the outside of clusters, T cells smoothly migrated at the mean velocity of $2.95 \pm 1.19 \mu \mathrm{m} / \mathrm{min}$, consistent with previous results ${ }^{10}$, and was not affected by control-IgG treatment (data not shown). Treatment with KBA also attenuated ear swelling significantly (Fig. 3c), as well as IFN- $\gamma$ production by skin $\mathrm{CD}^{+} \mathrm{T}$ cells (Fig. 3d, e). These results suggest that DC-effector T cell conjugates are integrin-dependent, similar to the DC-naïve T cell interactions in draining LNs.

\section{Skin macrophages are required for dDC clustering}

We next examined the initiation factors of DC-T cell accumulation. dDC clusters were also formed in response to the initial application of hapten (sensitization phase), but their number was significantly decreased $48 \mathrm{~h}$ after sensitization, while DC clusters persisted for $48 \mathrm{~h}$ in the elicitation phase (Fig. 4a and Supplementary Fig. 3a). These DC clusters were abrogated 7 days after DNFB application (data not shown). These observations suggest that DC-T cell accumulation is initiated by DC clustering, which then induces the accumulation, proliferation and activation of $\mathrm{T}$ cells, a process that depends on the presence of antigen-specific effector T cells in situ. DC clusters were also induced by solvents such as acetone or adjuvants such as dibutylphthalic acid and Mycobacterium bovis BCG-inoculation (Supplementary Fig. 3b, c). In addition, DC clusters were observed not only in the ear skin, but also in other regions such as the back skin and the footpad (Supplementary Fig. 3d). These results suggest that DC cluster formation is not an ear-specific event, but a general mechanism during skin inflammation.

The initial DC clusters were not decreased in recombination activating gene 2 (RAG2)-deficient mice, in which T and B cells are absent, in lymphoid tissue inducer cell-deficient aly/aly mice ${ }^{11}$ or in mast cell or basophil-depleted mice, using MasTRECK or BasTRECK mice ${ }^{12,13}$ (Fig. 4b). In contrast, DC clusters were abrogated in C57BL/6 mice transferred with BM from LysM-DTR mice, in which both macrophages and neutrophils 
were depleted by treatment with DT (Fig. 4b, c). The depletion of neutrophils alone, by administration of anti-Ly6G antibody (1A8), did not interfere with DC cluster formation (Fig. 4b), which suggested that macrophages, but not neutrophils, were required during the formation of DC clusters. Of note, DC cluster formation was not attenuated by anti-LFA-1 neutralizing KBA antibody treatment (Supplementary Fig. 3e, f), suggesting that macrophages-DCs interaction were LFA-1-independent. Consistent with the DC cluster formation, the elicitation of the CHS response (Fig. 4d) and IFN- $\gamma$ production by skin T cells (Fig. 4e) were significantly suppressed in LysM-DTR BM chimeric mice treated with DT. Thus, skin macrophages were required for formation of DC clusters, which was necessary for $\mathrm{T}$ cell activation and the elicitation of CHS.

\section{Macrophages are required for perivascular DCs clustering}

To examine the kinetics of dermal macrophage and DCs in vivo, we visualized them by two-photon microscopy. In vivo labeling of blood vessels with tetramethylrhodamine isothiocyanate (TRITC)-conjugated dextran revealed that dDCs distributed diffusely in the steady state (Fig. 5a, left). After hapten-application to the ear of previously sensitized mice, dDCs accumulated mainly around post-capillary venules (Fig. 5a, right and Fig. 5b). Time-lapse imaging revealed that some of dDCs showed directional migration toward TRITC-positive cells that were labeled red by incorporating extravasated TRITC-dextran (Fig. 5c and Supplementary Movie 4). The majority of TRITC-positive cells were F4/80 $\mathrm{CD}_{11} \mathrm{~b}^{+}$macrophages (Supplementary Fig. 4a). These observations prompted us to examine the role of macrophages in DC accumulation. We used a chemotaxis assay to determine whether macrophages attracted the DCs. dDCs and dermal macrophages were isolated from dermal skin cell suspensions and incubated in a transwell assay for $12 \mathrm{~h}$. dDCs placed in the upper wells efficiently migrated to the lower wells that contain dermal macrophages (Fig. 5d). But this dDC migration was not observed when macrophages were absent in the lower wells (Fig. 5d). Thus, dermal macrophages have a capacity to attract dDCs in vitro, which may lead to dDC accumulation around post-capillary venules.

\section{IL-1 $\alpha$ is required for DC cluster formation upon antigen challenge}

We attempted to explore the underlying mechanism of DC cluster formation. We observed that DC accumulation occurred during the first application of hapten (Fig. 4a), which suggested that an antigen-nonspecific mechanism, such as production of the 
218

219

220

221

222

223

224

225

226

227

228

229

230

231

232

233

234

235

236

237

238

239

240

241

242

243

244

245

246

247

248

249

250

pro-inflammatory mediator IL-1, may initiate DC clustering. Hapten-induced DC accumulation was not decreased in NALP3- or caspase-1-11-deficient mice, but was decreased significantly in IL-1R1-deficient mice, which lack a receptor for IL-1 $\alpha$, IL-1 $\beta$, and IL-1R antagonist, or after the subcutaneous administration of an IL-1R antagonist (Fig. 6a,b). Consistent with these observations, the elicitation of CHS and IFN- $\gamma$ production by skin T cells were significantly attenuated in mice that lack both IL-1 $\alpha$ and IL-1 $\beta$ (Fig. 6c, d). In addition, the formation of dDC clusters was suppressed significantly by the subcutaneous injection of an anti-IL-1 $\alpha$ neutralizing antibody, but only marginally by an anti-IL-1 $\beta$ neutralizing antibody (Fig. 6b). Because keratinocytes are known to produce IL-1 $\alpha$ upon hapten application ${ }^{14}$, our results suggest that IL-1 $\alpha$ has a major role in mediating the formation of DC clustering.

\section{M2 macrophages produce CXCL2 to attract dDCs}

To further characterize how macrophages attract dDCs, we examined Il1r1 expression in BM-derived M1 and M2 macrophages, classified as such based on the differential mRNA expression of Tnf, Nos2, Il12a, Arg1, Retnla and Chi313 (Supplementary Fig. 4b) ${ }^{15}$. We found that M2 macrophages had higher expression of Il1r1 mRNA compared to M1 macrophages (Fig. 6e). We also found that the subcutaneous injection of pertussis toxin, a inhibitory regulative $\mathrm{G}$ protein (Gi)-specific inhibitor, almost completely abrogated DC cluster formation in response to hapten-stimuli (Fig. 6b) suggesting that signaling through Gi-coupled chemokines was required for DC cluster formation.

We next used microarrays to examine the effect of IL-1 $\alpha$ on the expression of chemokines in M1 and M2 macrophages. IL-1 $\alpha$ treatment did not enhance chemokine expression in M1 macrophages, whereas it increased Ccl5, Ccl17, Ccl22 and Cxcl2 mRNA expression in M2 macrophages (Supplementary Table 1). Among them, Cxcl2 expression was enhanced most prominently by treatment with IL-1 $\alpha$, a result validated by real-time polymerase chain reaction (PCR) analysis (Fig. 6f). Consistently, Cxcl2 mRNA expression was significantly increased in DNFB-painted skin (Supplementary Fig. 5a) and was not affected by neutrophil depletion with 1A8 (Supplementary Fig. 5b, c). In addition, IL-1 $\alpha$-treated dermal macrophages produced Cxcl2 mRNA in vitro (Supplementary Fig. 5d). These results suggest that dermal macrophages, but not neutrophils, are the major source of CXCL2 during CHS. We also detected high expression of the mRNA for Cxcr2, the receptor for CXCL2, in DCs (Supplementary Fig. 5e), which prompted us to examine the role of CXCR2 on dDCs. 
The formation of DC clusters in response to hapten stimuli was substantially reduced by the intraperitoneal administration of the CXCR2 inhibitor SB265610 ${ }^{16}$ (Fig. 6g). In addition, SB265610-treatment during the elicitation of CHS inhibited ear swelling (Fig. 6h) and IFN- $\gamma$ production by skin T cells (Fig. 6i).

Taken together, in the absence of effector $\mathrm{T}$ cells specific for a cognate antigen (i.e. in the sensitization phase of CHS), DC clustering is a transient event, and hapten-carrying DCs migrate into draining LNs to establish sensitization. On the other hand, in the presence of the antigen and antigen-specific effector or memory T cells, DC clustering is followed by T cell accumulation (i.e. in the elicitation phase of CHS) (Supplementary Fig. 6). Thus, dermal macrophages are essential for initiating DC cluster formation through the production of CXCL2, and that DC clustering plays an important role for efficient activation of skin T cells.

\section{DISCUSSION}

Although the mechanistic events in the sensitization phase in cutaneous immunity have been studied thoroughly over 20 years ${ }^{17,18}$, what types of immunological events occur during the elicitation phases in the skin has remained unclear. Here we describe the antigen-dependent induction of DC and T cell clusters in the skin in a murine model of CHS and show that effector T cells-DCs interactions in these clusters are required to induce efficient antigen-specific immune responses in the skin. We show that dDCs, but not epidermal LCs, are essential for antigen presentation to skin effector $\mathrm{T}$ cells and they exhibit sustained association with effector T cells in an antigen- and LFA-1-dependent manner. IL-1 $\alpha$, and not the inflammasome, initiates the formation of these perivascular DC clusters.

Epidermal contact with antigens triggers release of IL-1 in the skin ${ }^{14}$. Previous studies have shown that the epidermal keratinocytes constitute a major reservoir of IL-1 $\alpha^{6}$ and mechanical stress to keratinocytes permits release of large amounts of IL-1 $\alpha$ even in the absence of cell death $^{19}$. The cellular source of IL-1 $\alpha$ in this process remains unclear. We show that IL-1 $\alpha$ activates macrophages that subsequently attract dDCs, mainly to areas around post-capillary venules, where effector $\mathrm{T}$ cells are known to transmigrate from the blood into the $\operatorname{skin}^{20}$. In the presence of the antigen and antigen-specific effector T cells, DC clustering is followed by $\mathrm{T}$ cell accumulation. Therefore, we propose that these perivascular $\mathrm{dDC}$ clusters may provide antigen-presentation sites for efficient effector $\mathrm{T}$ cell activation. This is suggested by the observations that CHS responses and intracutaneous $\mathrm{T}$ cell activation were attenuated 
284

285

286

287

288

289

290

291

292

293

294

295

296

297

298

299

300

301

302

303

304

305

306

307

308

309

310

311

312

313

314

315

316

317

significantly in the absence of these clusters, in condition of macrophage depletion or inhibiting integrin functions, IL-1R signaling ${ }^{21,22}$ or CXCR2 signaling ${ }^{23}$.

In contrast to the skin, antigen presentations in other peripheral barrier tissues is relatively well understood. In submucosal areas, specific sentinel lymphoid structures called mucosa-associated lymphoid tissue (MALT), serve as peripheral antigen presentation sites ${ }^{24}$, and lymphoid follicles are present in the normal bronchi (bronchus-associated lymphoid tissue; BALT). These structures serve as antigen presentation sites in non-lymphoid peripheral organs. By analogy, the concept of skin-associated lymphoid tissue (SALT) was proposed in the early 1980's, based on findings that cells in the skin are capable of capturing, processing and presenting antigens ${ }^{25,26}$. However, the role of cellular skin components as antigen presentation sites has remained uncertain. Here we have identified an inducible structure formed by dermal macrophages, dDCs and effector T cells, which seem to accumulate sequentially. Because formation of this structure is essential for efficient effector T cell activation, these inducible leukocyte clusters may function as SALTs. Unlike MALTs, these leukocyte clusters are not found at steady state, but are induced during the development of an adaptive immune response. Therefore, these clusters may be better named as inducible SALTs (iSALT), similar to inducible BALTs (iBALT) in the lung ${ }^{27}$. In contrast to iBALTs, we could not identify naïve T cells or B cells in SALTs (data not shown), suggesting that the leukocyte clusters in the skin may be specialized for effector T cell activation but not for naïve T cell activation. Our findings suggest that approaches to the selective inhibition of this structure may have novel therapeutic benefit in inflammatory disorders of the skin.

\section{ACKNOWLEDGEMENTS}

We thank Dr. P. Bergstresser and Dr. J. Cyster for critical reading of our manuscript. This work was supported in part by Grants-in-Aid for Scientific Research from the Ministry of Education, Culture, Sports, Science and Technology of Japan.

\section{AUTHOR CONTRIBUTIONS}

Y.N., G.E., and K.K designed this study and wrote the manuscript. Y.N., G.E, S.N., S.O., S.H., N.K., A.O., A.K., T.H., and S.N. performed the experiments and data analysis. S.T. and Y.S. did experiments related to microarray analysis. J.F. and E. G-Y did experiments related to immunohistochemistry of human samples. K.J.I, H.T., H. Y, Y. I., L.G.N., and M.K. 
318 developed experimental reagents and gene-targeted mice. T.O., Y.M., and K.K. directed the 319 project and edited the manuscript. All authors reviewed and discussed the manuscript. 320

321

322

COMPETENG FINANCIAL INTERESTS

323 The authors declare no competing financial interests.

324

325

326

ACCESSION CODES

327 Microarray data have been deposited in NCBI-GEO under accession number GSE53680. 328 
Natsuaki et al

330

331

332

333

334

335

336

337

338

339

340

341

342

343

344

345

346

\section{REFERENCES}

1. von Andrian UH, Mempel TR. Homing and cellular traffic in lymph nodes. Nat Rev Immunol 2003, 3(11): 867-878.

2. Clark RA, Chong B, Mirchandani N, Brinster NK, Yamanaka K, Dowgiert RK, et al. The vast majority of CLA+ T cells are resident in normal skin. J Immunol 2006, 176(7): 4431-4439.

3. Wang L, Bursch LS, Kissenpfennig A, Malissen B, Jameson SC, Hogquist KA. Langerin expressing cells promote skin immune responses under defined conditions. $J$ Immunol 2008, 180(7): 4722-4727.

4. Tuckermann JP, Kleiman A, Moriggl R, Spanbroek R, Neumann A, Illing A, et al. Macrophages and neutrophils are the targets for immune suppression by glucocorticoids in contact allergy. J Clin Invest 2007, 117(5): 1381-1390.

5. Sims JE, Smith DE. The IL-1 family: regulators of immunity. Nat Rev Immunol 2010, 10(2): 89-102.

6. Murphy JE, Robert C, Kupper TS. Interleukin-1 and cutaneous inflammation: a crucial link between innate and acquired immunity. J Invest Dermatol 2000, 114(3): 602-608.

7. Nakae S, Komiyama Y, Narumi S, Sudo K, Horai R, Tagawa Y, et al. IL-1-induced tumor necrosis factor-alpha elicits inflammatory cell infiltration in the skin by inducing IFN-gamma-inducible protein 10 in the elicitation phase of the contact hypersensitivity response. Int Immunol 2003, 15(2): 251-260.

8. Thyssen JP, Linneberg A, Menne T, Nielsen NH, Johansen JD. Contact allergy to allergens of the TRUE-test (panels 1 and 2) has decreased modestly in the general population. Br J Dermatol 2009, 161(5): 1124-1129.

9. Springer TA, Dustin ML. Integrin inside-out signaling and the immunological synapse. Curr Opin Cell Biol 2012, 24(1): 107-115. 
Natsuaki et al

364

365

366

367

368

369

370

371

372

373

374

375

376

377

378

379

380

381

382

383

384

385

386

387

388

389

390

391

392

393

394

395

396

10. Egawa G, Honda T, Tanizaki H, Doi H, Miyachi Y, Kabashima K. In vivo imaging of T-cell motility in the elicitation phase of contact hypersensitivity using two-photon microscopy. J Invest Dermatol 2011, 131(4): 977-979.

11. Miyawaki S, Nakamura Y, Suzuka H, Koba M, Yasumizu R, Ikehara S, et al. A new mutation, aly, that induces a generalized lack of lymph nodes accompanied by immunodeficiency in mice. Eur J Immunol 1994, 24(2): 429-434.

12. Sawaguchi M, Tanaka S, Nakatani Y, Harada Y, Mukai K, Matsunaga Y, et al. Role of mast cells and basophils in IgE responses and in allergic airway hyperresponsiveness. J Immunol 2012, 188(4): 1809-1818.

13. Otsuka A, Kubo M, Honda T, Egawa G, Nakajima S, Tanizaki H, et al. Requirement of interaction between mast cells and skin dendritic cells to establish contact hypersensitivity. PLoS One 2011, 6(9): e25538.

14. Enk AH, Katz SI. Early molecular events in the induction phase of contact sensitivity. Proc Natl Acad Sci U S A 1992, 89(4): 1398-1402.

15. Weisser SB, McLarren KW, Kuroda E, Sly LM. Generation and characterization of murine alternatively activated macrophages. Methods Mol Biol 2013, 946: 225-239.

16. Liao L, Ning Q, Li Y, Wang W, Wang A, Wei W, et al. CXCR2 blockade reduces radical formation in hyperoxia-exposed newborn rat lung. Pediatr Res 2006, 60(3): 299-303.

17. Honda T, Egawa G, Grabbe S, Kabashima K. Update of immune events in the murine contact hypersensitivity model: toward the understanding of allergic contact dermatitis. J Invest Dermatol 2013, 133(2): 303-315.

18. Kaplan DH, Igyarto BZ, Gaspari AA. Early immune events in the induction of allergic contact dermatitis. Nat Rev Immunol 2012, 12(2): 114-124. 
Natsuaki et al

398

399

400

401

402

403

404

405

406

407

408

409

410

411

412

413

414

415

416

417

418

419

420

421

422

423

424

19. Lee RT, Briggs WH, Cheng GC, Rossiter HB, Libby P, Kupper T. Mechanical deformation promotes secretion of IL-1 alpha and IL-1 receptor antagonist. J Immunol 1997, 159(10): 5084-5088.

20. Sackstein R, Falanga V, Streilein JW, Chin YH. Lymphocyte adhesion to psoriatic dermal endothelium is mediated by a tissue-specific receptor/ligand interaction. $J$ Invest Dermatol 1988, 91(5): 423-428.

21. Kish DD, Gorbachev AV, Fairchild RL. IL-1 receptor signaling is required at multiple stages of sensitization and elicitation of the contact hypersensitivity response. $J$ Immunol 2012, 188(4): 1761-1771.

22. Kondo S, Pastore S, Fujisawa H, Shivji GM, McKenzie RC, Dinarello CA, et al. Interleukin-1 receptor antagonist suppresses contact hypersensitivity. J Invest Dermatol 1995, 105(3).

23. Cattani F, Gallese A, Mosca M, Buanne P, Biordi L, Francavilla S, et al. The role of CXCR2 activity in the contact hypersensitivity response in mice. Eur Cytokine Netw 2006, 17(1): 42-48.

24. Brandtzaeg P, Kiyono H, Pabst R, Russell MW. Terminology: nomenclature of mucosa-associated lymphoid tissue. Mucosal Immunol 2008, 1(1): 31-37.

25. Streilein JW. Skin-associated lymphoid tissues (SALT): origins and functions. J Invest Dermatol 1983, 80 Suppl: 12s-16s.

26. Egawa G, Kabashima K. Skin as a peripheral lymphoid organ: revisiting the concept of skin-associated lymphoid tissues. J Invest Dermatol 2011, 131(11): 2178-2185.

27. Moyron-Quiroz JE, Rangel-Moreno J, Kusser K, Hartson L, Sprague F, Goodrich S, et al. Role of inducible bronchus associated lymphoid tissue (iBALT) in respiratory immunity. Nat med 2004, 10(9): 927-934.

28. Kissenpfennig A, Henri S, Dubois B, Laplace-Builhe C, Perrin P, Romani N, et al. 
Natsuaki et al

Dynamics and function of Langerhans cells in vivo: dermal dendritic cells colonize lymph node areas distinct from slower migrating Langerhans cells. Immunity 2005, 22(5): 643-654.

29. Jung S, Unutmaz D, Wong P, Sano G, De los Santos K, Sparwasser T, et al. In vivo depletion of CD11c+ dendritic cells abrogates priming of CD8+ T cells by exogenous cell-associated antigens. Immunity 2002, 17(2): 211-220.

30. Lindquist RL, Shakhar G, Dudziak D, Wardemann H, Eisenreich T, Dustin ML, et al. Visualizing dendritic cell networks in vivo. Nat immunol 2004, 5(12): 1243-1250.

31. Miyake Y, Kaise H, Isono K, Koseki H, Kohno K, Tanaka M. Protective role of macrophages in noninflammatory lung injury caused by selective ablation of alveolar epithelial type II Cells. J Immunol 2007, 178(8): 5001-5009.

32. Hao Z, Rajewsky K. Homeostasis of peripheral B cells in the absence of B cell influx from the bone marrow. J Exp Med 2001, 194(8): 1151-1164.

33. Horai R, Asano M, Sudo K, Kanuka H, Suzuki M, Nishihara M, et al. Production of mice deficient in genes for interleukin (IL)-1alpha, IL-1beta, IL-1alpha/beta, and IL-1 receptor antagonist shows that IL-1beta is crucial in turpentine-induced fever development and glucocorticoid secretion. J Exp Med 1998, 187(9): 1463-1475.

34. Coban C, Igari Y, Yagi M, Reimer T, Koyama S, Aoshi T, et al. Immunogenicity of whole-parasite vaccines against Plasmodium falciparum involves malarial hemozoin and host TLR9. Cell Host Microbe 2010, 7(1): 50-61.

35. Martinon F, Petrilli V, Mayor A, Tardivel A, Tschopp J. Gout-associated uric acid crystals activate the NALP3 inflammasome. Nature 2006, 440(7081): 237-241.

36. Koedel U, Winkler F, Angele B, Fontana A, Flavell RA, Pfister HW. Role of Caspase-1 in experimental pneumococcal meningitis: Evidence from pharmacologic Caspase inhibition and Caspase-1-deficient mice. Ann Neurol 2002, 51(3): 319-329. 
Natsuaki et al

37. Tomura M, Honda T, Tanizaki H, Otsuka A, Egawa G, Tokura Y, et al. Activated 467 regulatory $\mathrm{T}$ cells are the major $\mathrm{T}$ cell type emigrating from the skin during a cutaneous immune response in mice. J Clin Invest 2010, 120(3): 883-893.

469

470 
471

472

473

474

475

476

477

478

479

480

481

482

483

484

485

486

487

488

489

490

491

492

493

494

495

496

497

498

499

500

501

502

503

\section{METHODS}

\section{Mice}

Female 8- to 12-week-old C57BL/6-background mice were used in this study. C57BL/6N mice were purchased from SLC (Shizuoka, Japan). Langerin-eGFP-DTR ${ }^{28}$, CD11c-DTR $^{29}$, CD11c-YFP ${ }^{30}$, LysM-DTR ${ }^{31}$, Rag2-deficient ${ }^{32}$, MasTRECK ${ }^{12,13}$, BasTRECK ${ }^{12,13}$, ALY/NscJcl-aly/aly ${ }^{11}$, IL-1 $\alpha / \beta$-deficient ${ }^{33}$, IL-1R1-deficient ${ }^{34}$, NLRP3-deficient ${ }^{35}$, and caspase-1/11-deficient mice ${ }^{36}$ were described previously. All experimental procedures were approved by the Institutional Animal Care and Use Committee of Kyoto University Graduate School of Medicine.

\section{Human Subjects}

Human skin biopsy samples were obtained from a nickel-reactive patch after $48 \mathrm{~h}$ from placement of nickel patch tests in patients with a previously proven allergic contact dermatitis. A biopsy of petrolatum-occluded skin was also obtained as a control. Informed consent was obtained under IRB approved protocols at the Icahn School of Medicine at Mount Sinai School Medical Center, and the Rockefeller University in New York.

\section{Induction of contact hypersensitivity (CHS) response}

Mice were sensitized on shaved abdominal skin with $25 \mu 10.5 \%(\mathrm{w} / \mathrm{v})$

1-fluoro-2,4-dinitrofluorobenzene (DNFB; Nacalai Tesque, Kyoto, Japan) dissolved in acetone/olive oil (4/1). Five days later, the ears were challenged with $20 \mu \mathrm{l} 0.3 \%$ DNFB. For adoptive transfer, T cells were magnetically sorted using auto MACS (Miltenyi Biotec, Bergisch Gladbach, Germany) from the draining LNs of sensitized mice and then transferred $1 \mathrm{x} 10^{7}$ cells intravenously into naïve mice.

\section{Depletion of cutaneous DC subsets, macrophages, and neutrophils}

To deplete all cutaneous DC subsets (including LCs), 6-week-old Langerin-DTR mice were irradiated (two doses of 550 Rad given $3 \mathrm{~h}$ apart) and were transferred with 1 x $10^{7} \mathrm{BM}$ cells from CD11c-DTR mice. Eight weeks later, $2 \mu \mathrm{g}$ diphtheria toxin (DT; Sigma-Aldrich, St. Louis, MO) was intraperitoneally injected. To selectively deplete LCs, irradiated Langerin-DTR mice were transferred with BM cells from C57BL/6 mice, and $1 \mu \mathrm{g}$ DT was injected. To selectively deplete dermal DCs, irradiated C57BL/6 mice were transferred with BM cells from CD11c-DTR mice, and $2 \mu \mathrm{g}$ DT was injected. For macrophage depletion, 
Natsuaki et al

504

505

506

507

508

509

510

511

512

513

514

515

516

517

518

519

520

521

522

523

524

525

526

527

528

529

530

531

532

533

534

535

536

irradiated C57BL/6 mice were transferred with BM cells from LysM-DTR mice and $800 \mathrm{ng}$ DT was injected. For neutrophil depletion, 0.5 mg/body anti-Ly6G antibody (1A8, BioXCell, Shiga, Japan) were intravenously administered to mice $24 \mathrm{~h}$ before experiment.

\section{Time-lapse imaging of cutaneous DCs, macrophages, and T cells}

Cutaneous DCs were observed using CD11c-YFP mice. To label cutaneous macrophages in vivo, 5 mg TRITC-dextran (Sigma-Aldrich) was intravenously injected and mice were left for $24 \mathrm{~h}$. At that time, cutaneous macrophages become fluorescent because they incorporated extravasated dextran. To label skin-infiltrating T cells, T cells from DNFB-sensitized mice were labeled with CellTracker Orange CMTMR (Invitrogen, Carlsbad, CA) and adoptively transferred. Keratinocytes and sebaceous glands were visualized with the subcutaneous injection of isolectin B4 (Invitrogen) and BODIPY (Molecular Probes, Carlsbad, CA), respectively. Mice were positioned on the heating plate on the stage of a two-photon microscope IX-81 (Olympus, Tokyo, Japan) and their ear lobes were fixed beneath a cover slip with a single drop of immersion oil. Stacks of 10 images, spaced $3 \mu \mathrm{m}$ apart, were acquired at 1 to 7 min intervals for up to $24 \mathrm{~h}$. To calculate T cell and DC velocities, movies from 3 independent mice were processed and analyzed using Imaris7.2.1 (Bitplane, South Windsor, CT) for each experiment.

\section{Histology and immunohistochemistry}

For histological examination, tissues were fixed with 10\% formalin in phosphate buffer saline, and then embedded in paraffin. Sections with a thickness of $5 \mu \mathrm{m}$ were prepared and subjected to staining with hematoxylin and eosin. For whole-mount staining, the ears were split into dorsal and ventral halves, and incubated with $0.5 \mathrm{M}$ ammonium thiocyanate for 30 min at $37^{\circ} \mathrm{C}^{37}$. Then the dermal sheets were separated and fixed in acetone for $10 \mathrm{~min}$ at $-20^{\circ} \mathrm{C}$. After treatment with Image-iT FX Signal Enhancer (Invitrogen), the sheets were incubated with anti-mouse MHC class II antibody (eBioscience, San Diego, CA) followed by incubation with secondary antibody conjugated to Alexa 488 or 594 (Invitrogen). The slides were mounted using a ProLong Antifade kit with DAPI (Molecular Probes) and observed under a fluorescent microscope (BZ-900, KEYENCE, Osaka, Japan). The number/size of DC clusters were evaluated in 10 fields of $1 \mathrm{~mm}^{2} /$ ear and were scored according to the criteria shown in Supplementary Fig. 5a. 


\section{Cell isolation and flow cytometry}

539 To isolate skin lymphocytes, the ear splits were put into digestion buffer

540 (RPMI supplemented with $2 \%$ fetal calf serum, $0.33 \mathrm{mg} / \mathrm{ml}$ of Liberase TL (Roche, Lewes, $541 \mathrm{UK}$ ), and $0.05 \%$ DNase I (Sigma-Aldrich)) for $1 \mathrm{hr}$ at $37^{\circ} \mathrm{C}$. After the incubation, the tissue was disrupted by passage through a $70 \mu \mathrm{m}$ cell strainer and stained with respective antibodies. For analysis of intracellular cytokine production, cell suspensions were obtained in the presence of $10 \mu \mathrm{g} / \mathrm{ml}$ of Brefeldine A (Sigma-Aldrich) and were fixed with Cytofix buffer, permeabilized with Perm/Wash buffer (BD Biosciences) as per the manufacturer's protocol. To stain cells, anti-mouse CD4, CD8, CD11b, CD11c, B220, MHC class II, F4/80, IFN- $\gamma$, Gr1 antibodies and 7-amino-actinomycin D (7AAD) were purchased from eBioscience. Anti-mouse CD45 antibody (BioLegend, San Diego, CA), anti-TCR- $\beta$ antibody (BioLegend), and anti-CD16/CD32 antibody (BD Biosciences) were purchased. Flow cytometry was performed using LSRFortessa (BD Biosciences) and analyzed with FlowJo (TreeStar, San

551 Carlos, CA).

552

\section{Chemotaxis assay}

554 Chemotaxis was performed as described previously with some modifications ${ }^{37}$. In brief, the dermis of the ear skin was minced and digested with $2 \mathrm{mg} / \mathrm{ml}$ collagenase type II (Worthington Biochemical, NY) containing $1 \mathrm{mg} / \mathrm{ml}$ hyaluronidase (Sigma-Aldrich) and 100 $\mu \mathrm{g} / \mathrm{ml}$ DNase I (Sigma-Aldrich) for $30 \mathrm{~min}$ at $37^{\circ} \mathrm{C}$. DDCs and macrophages were isolated using auto-MACS. Alternatively, BM-derived DCs and macrophages were prepared. 1 x $10^{6}$ DCs were added to the $5 \mu \mathrm{m}$ pore-size transwell insert (Corning, Cambridge, MA) and $5 \mathrm{x}$ $10^{5}$ macrophages were added into the lower wells, and the cells were incubated at $37^{\circ} \mathrm{C}$ for 12 h. A known number of fluorescent reference beads (FlowCount fluorospheres, Beckman Coulter, Fullerton, CA) were added to each sample to allow accurate quantification of migrated cells in the lower wells by flow cytometry.

\section{Cell proliferation assay with CellTrace ${ }^{\mathrm{TM}}$ Violet}

Mice were sensitized with $25 \mu \mathrm{l}$ 0.5\% DNFB or 7\% trinitrochlorobenzene (Chemical Industry, Tokyo, Japan). Five days later, T cells were magnetically separated from the draining LNs of each group, and labeled with CellTrace ${ }^{\mathrm{TM}}$ Violet (Invitrogen) as per the manufacturer's protocol. Ten million T cells were adoptively transferred to naïve mice, and the ears were 
570

571

572

573

574

575

576

577

578

579

580

581

582

583

584

585

586

587

588

589

590

591

592

593

594

595

596

597

598

599

600

601

602

challenged with $20 \mu \mathrm{l}$ of $0.5 \%$ DNFB. Twenty-four hours later, ears were collected and analyzed by flow cytometry.

\section{In vitro differentiation of DCs, M1 and M2-phenotype macrophages from BM cells}

BM cells from the tibias and fibulas were plated $5 \times 10^{6}$ cells $/ 10 \mathrm{~cm}$ dishes on day 0 . For DC differentiation, cells were cultured at $37^{\circ} \mathrm{C}$ in $5 \% \mathrm{CO}_{2}$ in cRPMI medium (RPMI supplemented with 1\% L-glutamine, 1\% Hepes, 0.1\% 2ME and 10\% fetal bovine serum) containing 10 ng/mL GM-CSF (Peprotech, Rocky Hill, NJ). For macrophages differentiation, BM cells were cultured in cRPMI containing $10 \mathrm{ng} / \mathrm{mL}$ M-CSF (Peprotech). Medium was replaced on days 3 and 6 and cells were harvested on day 9. To induce M1 or M2 phenotypes, cells were stimulated for $48 \mathrm{~h}$ with IFN- $\gamma(10 \mathrm{ng} / \mathrm{mL}$; R\&D Systems, Minneapolis, MN) or with IL-4 (20 ng/mL; R\&D Systems), respectively.

\section{In vitro IL-1 $\alpha$ stimulation assay of dermal macrophages}

Dermal macrophages were separated from IL- $1 \alpha / \beta$-deficient mice ${ }^{33}$ to avoid pre-activation during cell preparations. Ear splits were treated with $0.25 \%$ trypsin/EDTA for 30 min at $37^{\circ} \mathrm{C}$ to remove epidermis and then minced and incubated with collagenase as previously described.

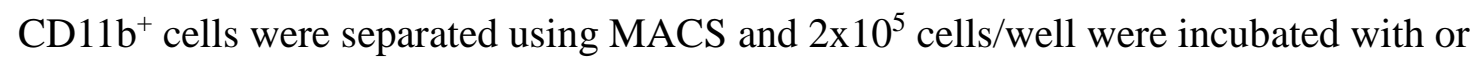
without $10 \mathrm{ng} / \mathrm{ml} \mathrm{IL-1} \alpha$ (R\&D systems) in 96-well plate for $24 \mathrm{~h}$.

\section{Blocking assay}

For LFA-1 blocking assay, mice were intravenously injected with $100 \mu$ g anti-LFA-1 neutralizing antibody, KBA, 12-14 h after challenge with $20 \mu \mathrm{l}$ 0.5\% DNFB. For IL-1R blocking, mice were subcutaneously injected with $10 \mu \mathrm{g}$ IL-1R antagonist (PROSPEC, East Brunswick, NJ) 5 h before challenge. For blocking of CXCR2, mice were intraperitoneally treated with $50 \mu \mathrm{g}$ CXCR2 inhibitor SB265610 ${ }^{16}$ (Tocris Bioscience, Bristol, UK) 6 h before and at hapten painting.

\section{Quantitative PCR analysis}

Total RNA was isolated using an RNeasy Mini kit (Qiagen, Hilden, Germany). cDNA was synthesized using a PrimeScript RT reagent kit (TaKaRa, Ohtsu, Japan) with random hexamers as per the manufacturer's protocol. Quantitative PCR was carried out with a LightCycler 480 using a LightCycler SYBR Green I master (Roche) as per the 
Natsuaki et al

603

manufacturer's protocol. The relative expression of each gene was normalized against that of

604 Gapdh. Primer sequences are shown in Supplementary Table 2.

605

606

\section{Microarray analysis}

607 Total RNA was isolated using the RNeasy Mini Kit (Qiagen) as per the manufacturers'

608 protocol. An amplified sense-strand DNA product was synthesized by the Ambion WT

609 Expression Kit (Life Technologies, Gaithersburg, MD), and was fragmented and labeled by

610 the WT Terminal Labeling and Controls Kit (Affymetrix, Santa Clara, CA), and was

611 hybridized to the Mouse Gene 1.0 ST Array (Affymetrix). We used the robust multi-array

612 average algorithm for $\log$ transformation $(\log 2)$ and normalization of the GeneChip data.

613 Microarray data have been deposited in NCBI-GEO under accession number GSE53680.

614

\section{General experimental design and statistical analysis}

616 For animal experiments, a sample size of three to five mice per group was determined on the

617 basis of past experience in generating statistical significance. Mice were randomly assigned

618 to study groups and no specific randomization or blinding protocol was used. Sample or

619 mouse identity was not masked for any of these studies. Statistical analyses were performed

620 using Prism software (GraphPad Software Inc.). Normal distribution was assumed a priori for

621 all samples. Unless indicated otherwise, an unpaired parametric $t$-test was used for

622 comparison of data sets. In cases in which the data point distribution was not Gaussian, a

623 nonparametric $t$-test was also applied. $P$ values of less than 0.05 were considered significant.

624

625

626 
627

628

629

630

631

632

633

634

635

636

637

638

639

640

641

642

643

644

645

646

647

648

649

650

651

652

653

654

655

656

657

658

659

\section{Figure Legends}

Figure 1: DC-T cell cluster formation is responsible for epidermal eczematous conditions.

(a) Clinical manifestations of allergic contact dermatitis in human skin $48 \mathrm{~h}$ after a patch test with nickel. Scale bar $=200 \mu \mathrm{m}$. (b) Hematoxylin and eosin, anti-CD3, and anti-CD11c staining of the human skin biopsy sample from an eczematous legion. Asterisks and arrowheads denote epidermal vesicles and $\mathrm{dDC}-\mathrm{T}$ cell clusters, respectively. Scale bar $=250$ $\mu \mathrm{m}$. (c) Sequential images of leukocyte clusters in the elicitation phase of CHS. White circles represent DC (green) and T cell (red) dermal accumulations. Scale bar $=100 \mu \mathrm{m}$. (d) A high magnification view of DC-T cell cluster in Fig.1c. Scale bar $=10 \mu \mathrm{m}$. (e) Intercellular edema of the epidermis overlying DC-T cell cluster in the dermis. Keratinocytes (red) are visualized with isolectin B4. The right panel shows the mean distance between adjacent keratinocytes above (+) or not above (-) DC-T cell cluster (n=20, each). Scale bar $=10 \mu \mathrm{m}$. (f) Ear swelling $24 \mathrm{~h}$ after CHS in subset-specific DC-depletion models ( $\mathrm{n}=5$, each). ${ }^{*}, P<0.001$. (g) The number (left) and the \% frequency (right) of IFN- $\gamma$ producing T cells in the ear $18 \mathrm{~h}$ after CHS with or without dDC-depletion ( $\mathrm{n}=5$, each). ${ }^{*}, P<0.05$.

Figure 2: Antigen-dependent T cell proliferation in DC-T cell clusters. (a) T cell proliferation in the skin. $\mathrm{CD}^{+}$and $\mathrm{CD}^{+} \mathrm{T}$ cells from DNFB- (red) or TNCB- (blue) sensitized mice were labeled with CellTrace ${ }^{\mathrm{TM}}$ Violet and transferred. The dilutions of tracer in the challenged sites were examined $24 \mathrm{~h}$ later. (b) Conjugation time of DNFB- (red, $\mathrm{n}=$ 160) or TNCB-sensitized (blue, $\mathrm{n}=60$ ) T cells with dDCs $24 \mathrm{~h}$ after DNFB challenge. ${ }^{*}, P<$ 0.05. (c) Sequential images of dividing T cells (red) in DC-T cell clusters. Green represents dDCs. Arrowheads represent a dividing T cell.

Figure 3: LFA-1 is essential for the persistence of DC-T cell clustering and for T cell activation in the skin. (a) DC (green) and T cell (red) clusters in the DNFB-challenged site before $(0 \mathrm{~h})$ and $9 \mathrm{~h}$ after KBA or isotype-matched IgG treatment. Scale bar $=100 \mu \mathrm{m}$. (b) Fold changes of T cell velocities in DNFB-challenged sites after KBA or control IgG treatment ( $\mathrm{n}=30$, each). (c) Ear swelling $24 \mathrm{~h}$ after KBA (red) or control IgG (black) treatment with DNFB challenge ( $\mathrm{n}=5$, each). $(\mathbf{d}$ and $\mathbf{e})$ IFN- $\gamma$ production by CD8 ${ }^{+} \mathrm{T}$ cells $(\mathrm{d})$ and the number of IFN- $\gamma$ producing cells in $\mathrm{CD}^{+}$or $\mathrm{CD}^{+}$populations (e) in KBA (red) or control IgG (black) treated mice $(\mathrm{n}=5$, each). DNFB-sensitized mice were treated with KBA or control IgG $12 \mathrm{~h}$ after DNFB challenge and the skin samples were obtained $6 \mathrm{~h}$ later. *, $P$ 
660

661

662

663

664

665

666

667

668

669

670

671

672

673

674

675

676

677

678

679

680

681

682

683

684

685

686

687

688

689

690

691

692

$<0.05$.

Figure 4: Macrophages are essential for DC cluster formation. (a) Score of DC cluster number $24 \mathrm{~h}$ and $48 \mathrm{~h}$ after DNFB application in sensitization (red) or elicitation (green) phase of CHS ( $\mathrm{n}=4$, each). (b) Score of DC cluster number in non-treated (NT) mice and DNFB-applicated-C57BL/6 (WT), Rag2-deficient, aly/aly, MasTRECK, BasTRECK, LysM-DTR, and 1A8-treated mice (n=4, each). *, $P<0.05$. (c) DC clusters observed in LysM-DTR BM chimeric mice with or without DT-treatment. Scale bar $=100 \mu \mathrm{m}$. (d) Ear swelling $24 \mathrm{~h}$ after DNFB application in LysM-DTR BM chimeric mice with (red) or without (black) DT-treatment ( $\mathrm{n}=5$, each). (e) The number (left) and the \% frequency (right) of IFN- $\gamma$ producing $\mathrm{CD}^{+} \mathrm{T}$ cells in the ear $18 \mathrm{~h}$ after DNFB application in LysM-DTR BM chimeric mice with (red) or without (black) DT-treatment (n= 5, each). ${ }^{*}, P<0.05$.

Figure 5: Macrophages mediate perivascular DC cluster formation. (a) A distribution of $\mathrm{dDCs}$ (green) in the steady state (left) and in the elicitation phase of CHS (right). The white circles show DC clusters. Sebaceous glands visualized with BODIPY (green) are indicated by arrows. Blood vessels, yellow/red; macrophages, red. (b) A high magnification view of perivascular DC cluster. Scale bar $=100 \mu \mathrm{m}$.(c) Sequential images of dDCs (green) and macrophages (red) in the elicitation phase of CHS. The white dashed line represents the track of a DC. (d) Chemotaxis assay. \% input of dDCs transmigrating into the lower chamber with or without macrophages prepared from the skin.

Figure 6: IL-1 $\alpha$ upregulates CXCR2 ligands expression in M2-phenotype macrophages to form DC clusters. (a) Scores of DC cluster numbers in NT or $24 \mathrm{~h}$ after hapten-painted sites in WT, IL-1R-, NALP3-, or caspase 1 (Casp1)-deficient mice (n=4, each). (b) Scores of DC cluster numbers in NT or $24 \mathrm{~h}$ after hapten-painted sites in isotype control IgG, anti-IL- $\alpha$ antibody, anti-IL-1 $\beta$ antibody, IL-1R antagonist, or pertussis toxin (Ptx)-treated mice ( $\mathrm{n}=4$, each). (c, d) Ear swelling $24 \mathrm{~h}$ after DNFB application (c) and the number (left) and the \% frequency (right) of IFN- $\gamma$ producing $\mathrm{CD}^{+} \mathrm{T}$ cells in the ear $18 \mathrm{~h}$ after DNFB application (d) in mice that lack both IL-1 $\alpha$ and IL-1 $\beta$ (red) and WT (black) mice ( $\mathrm{n}=5$, each) which were adoptively transferred with DNFB-sensitized T cells. ${ }^{*}, P<0.05$. (e, f) Relative amount of Il1r1 and Cxcl2 mRNA expression. Quantitative RT-PCR analysis of mRNA obtained from M1 or M2-phenotype macrophages (e), cultured with (+) or without (-) 
693 IL-1 $\alpha$ (f) (n=4, each). (g) Scores of DC cluster numbers in NT or $24 \mathrm{~h}$ after hapten-painted 694 sites in the presence (SB265610) or absence (vehicle) of a CXCR2 inhibitor (n=4, each). *, $P$

$695<0.05$. (h, i) Ear swelling $24 \mathrm{~h}$ after DNFB application (h) and the number (right) and the \% 696 frequency (left) of IFN- $\gamma$ producing $\mathrm{CD}^{+} \mathrm{T}$ cells $18 \mathrm{~h}$ after DNFB application (i) with (red) 697 or without (black) SB265610-treatment (n =5, each). *, $P<0.05$. 
Figure 1

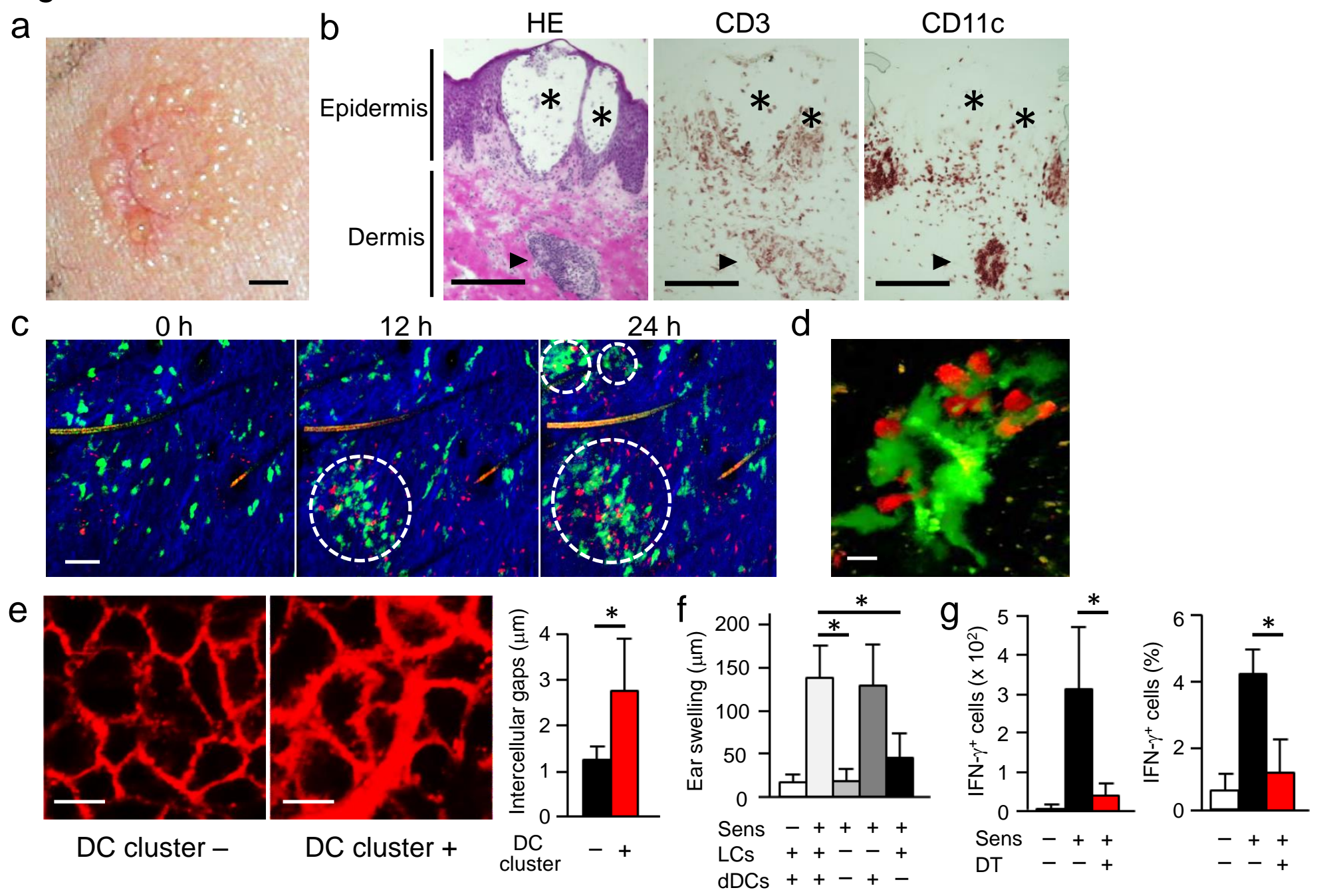




\section{Figure 2}
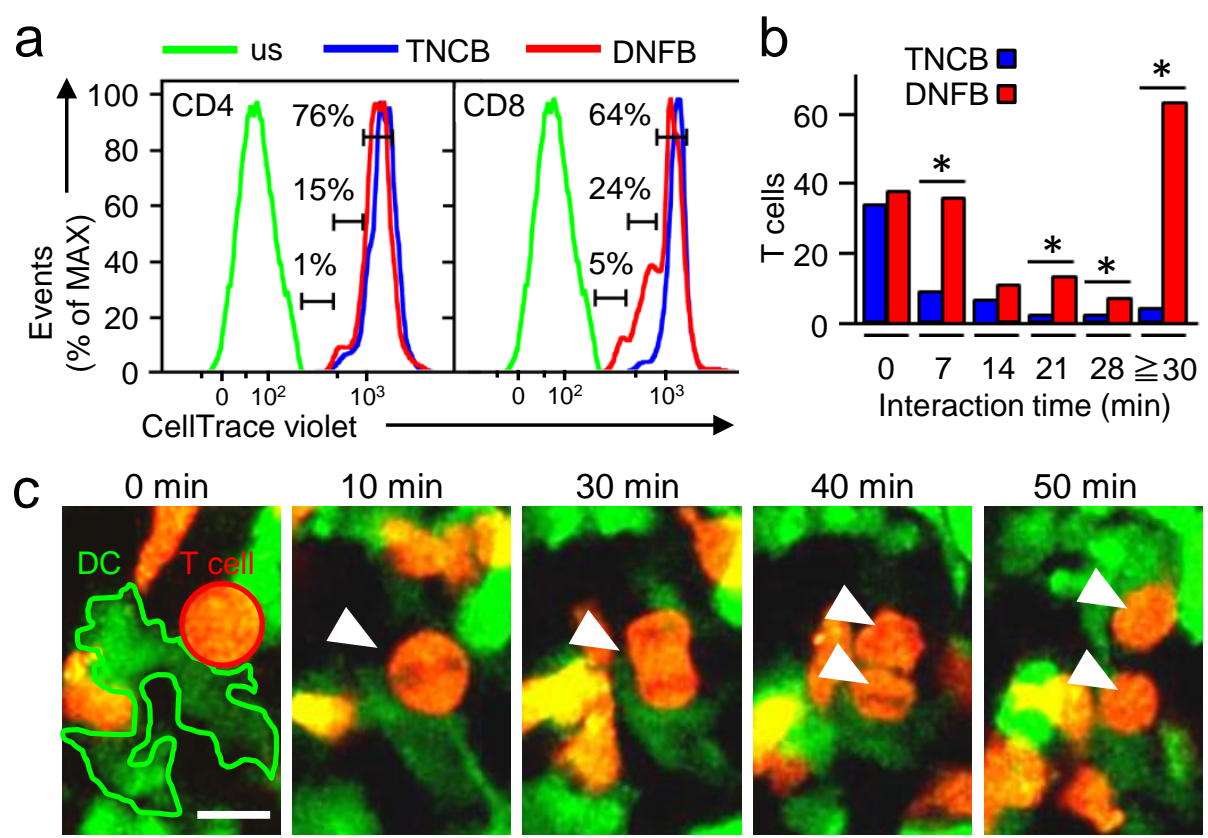

$30 \mathrm{~min}$

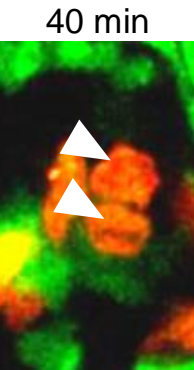

$50 \mathrm{~min}$
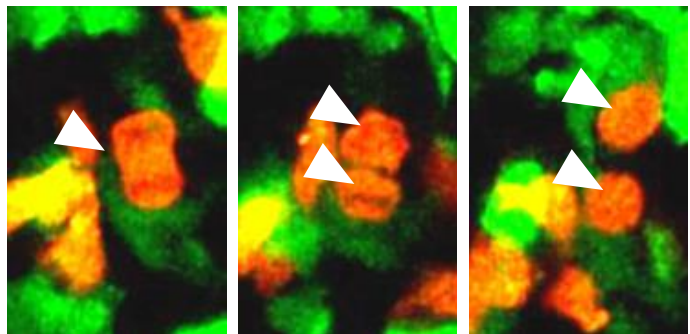


\section{Figure 3}
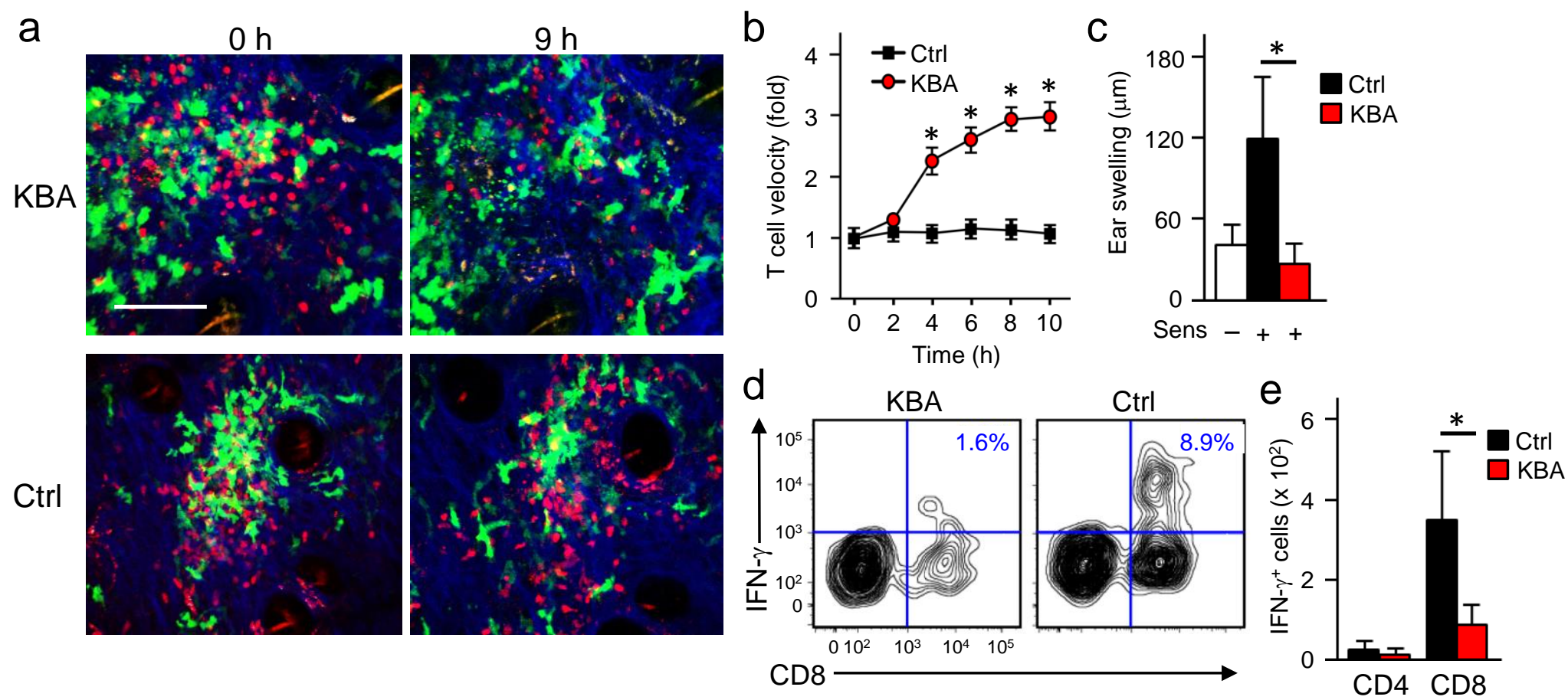


\section{Figure 4}

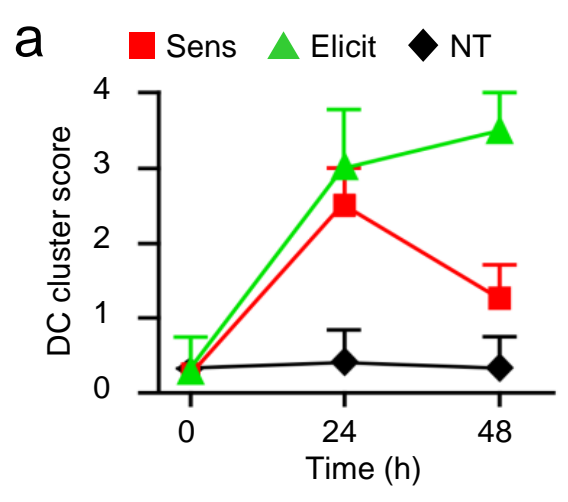

b
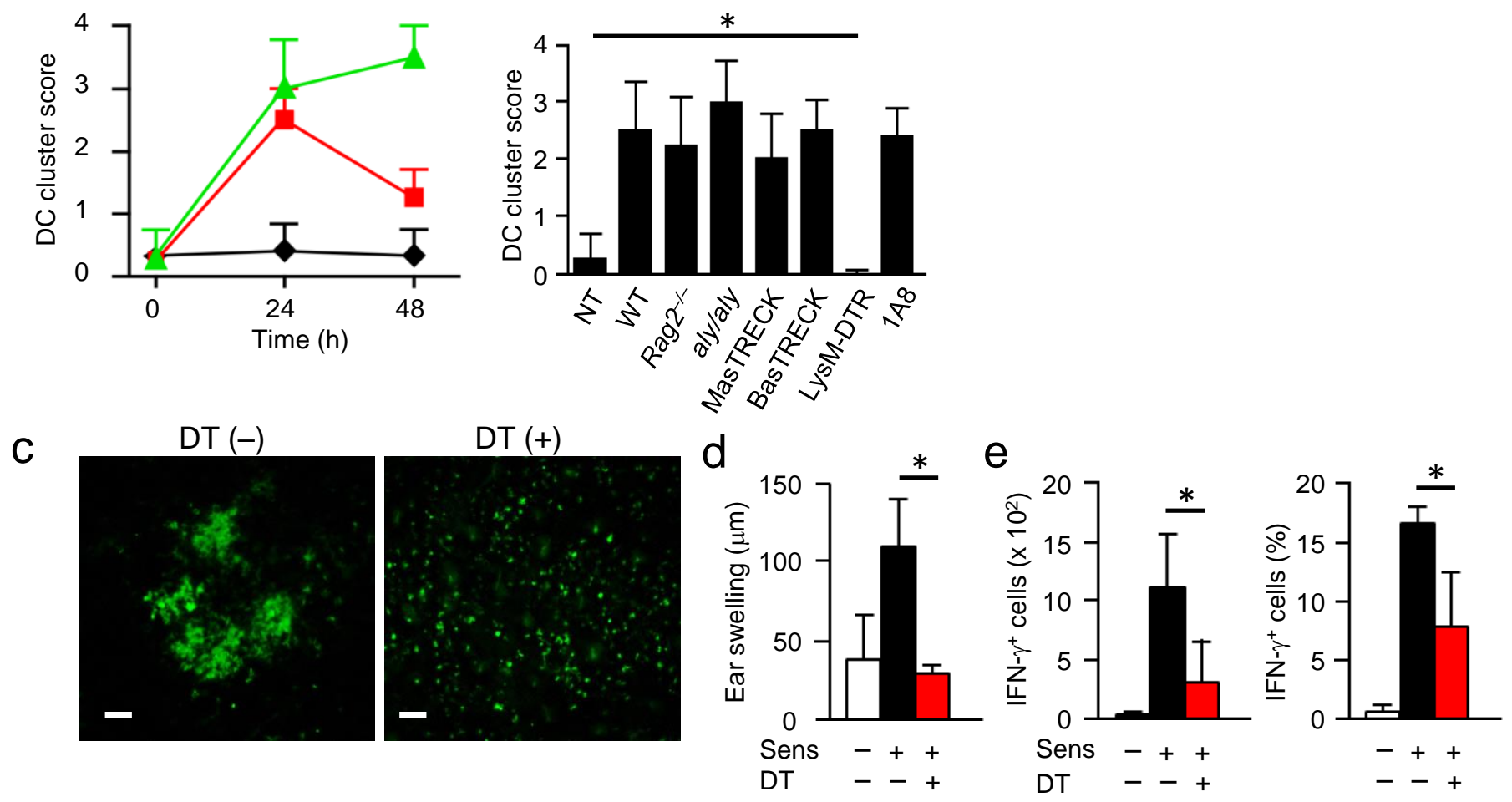
Figure 5
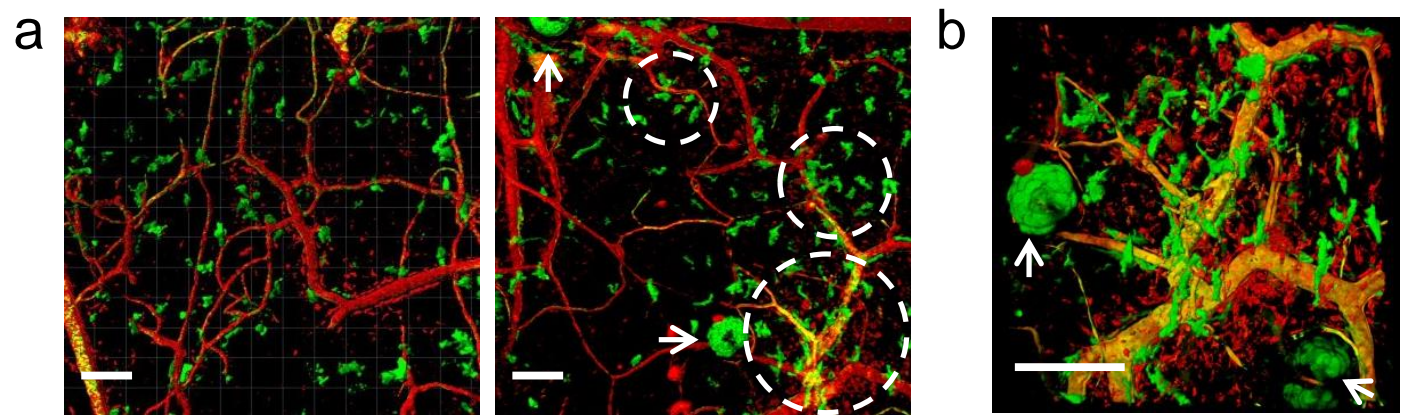

C

0 min

$12 \min$

$24 \min$

d
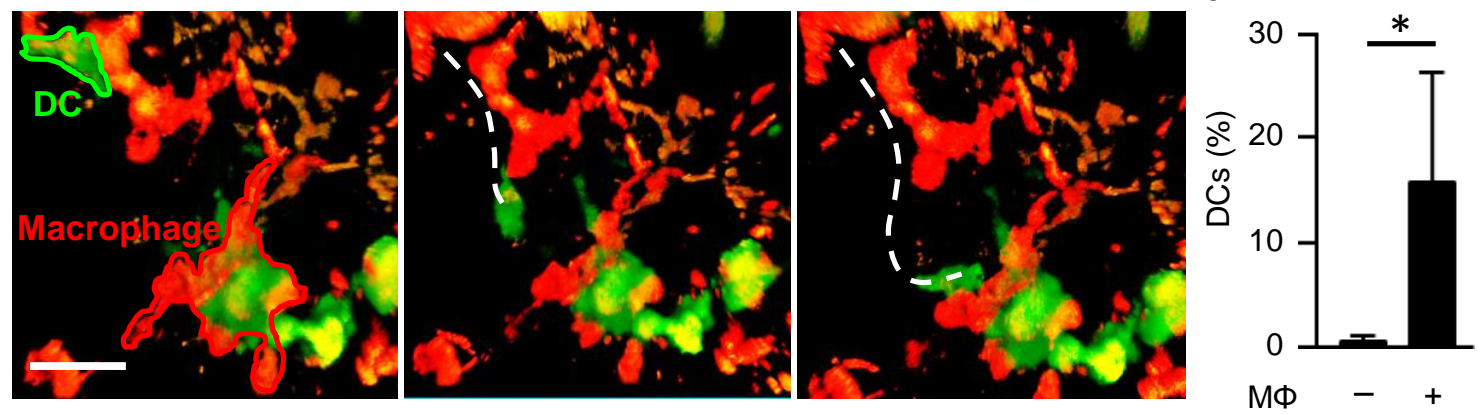
Figure 6
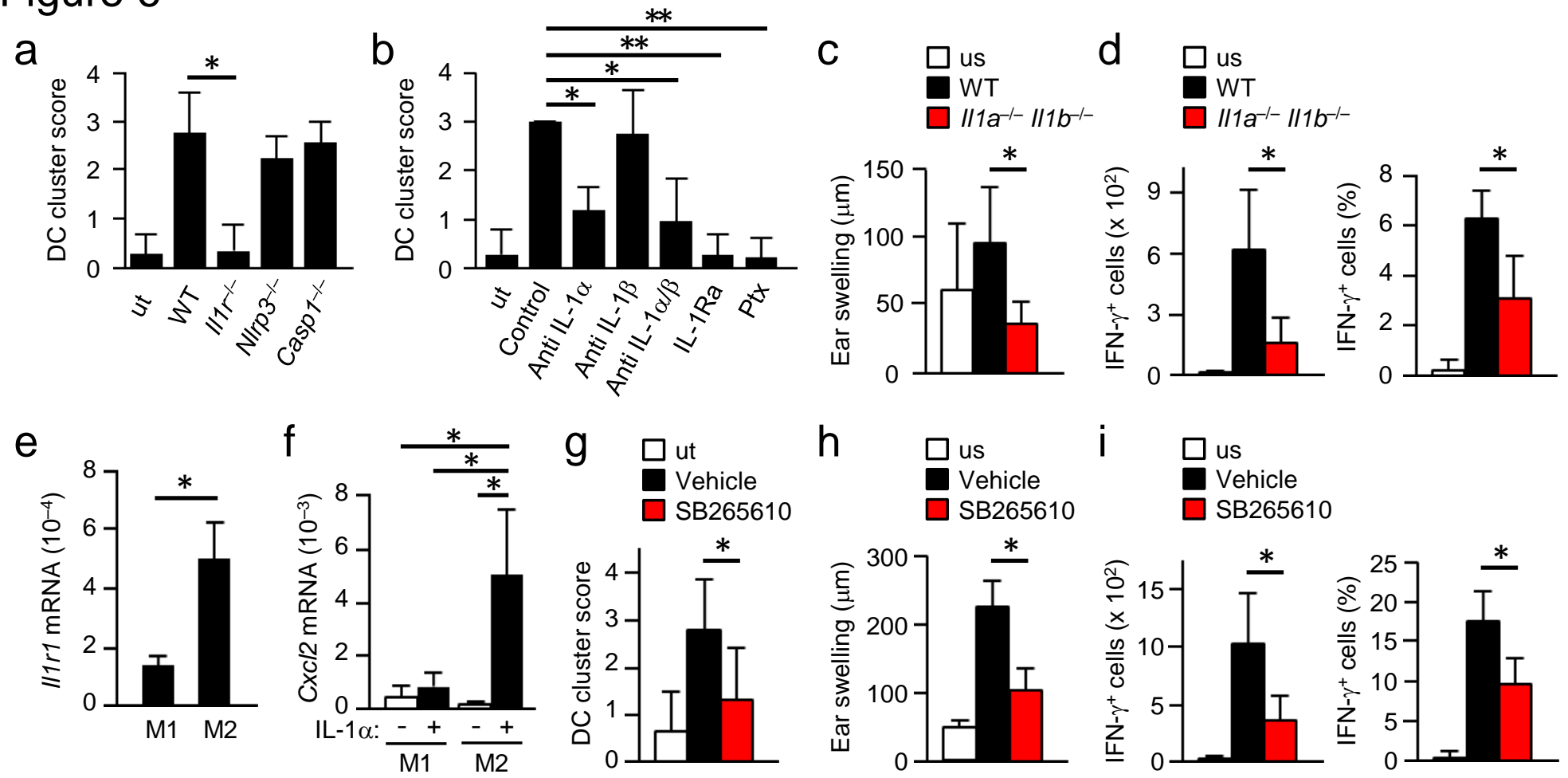

h $\square$ us

$\square$ Vehicle
$\square$ SB265610
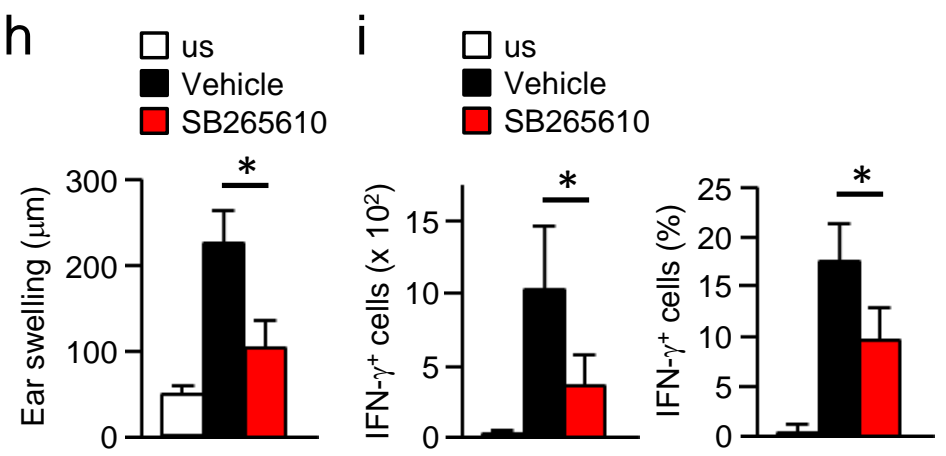


\section{Supplementary Figure 1}
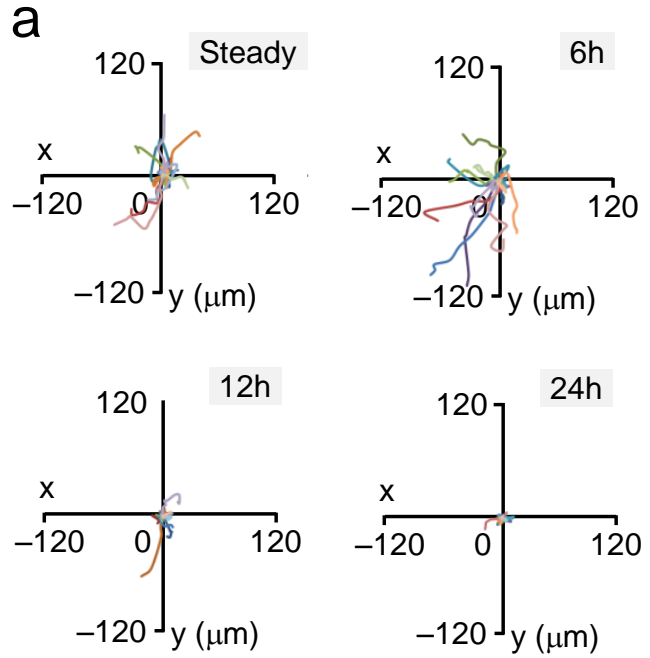

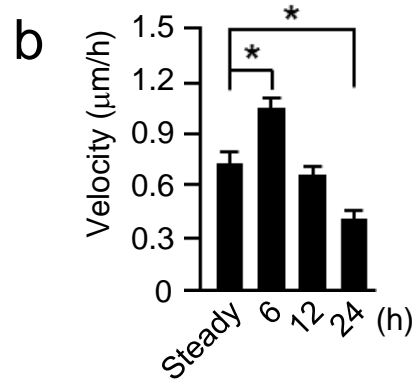

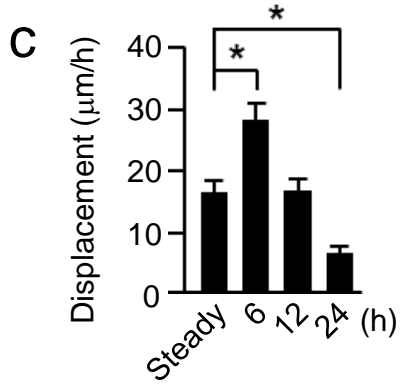




\section{Supplementary Figure 2}

a

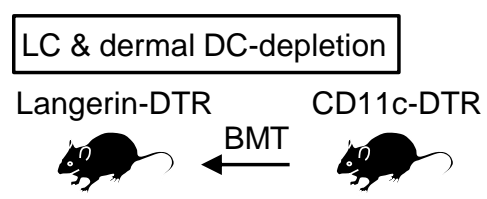

\section{LC-depletion}

Langerin-DTR

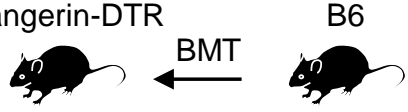

Dermal DC-depletion

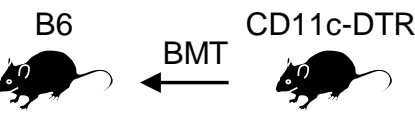

b

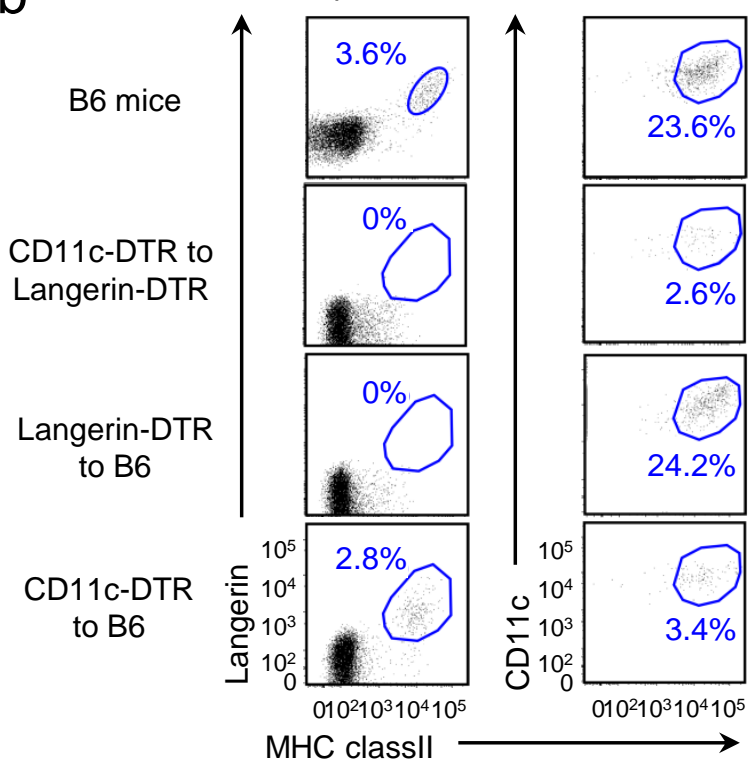

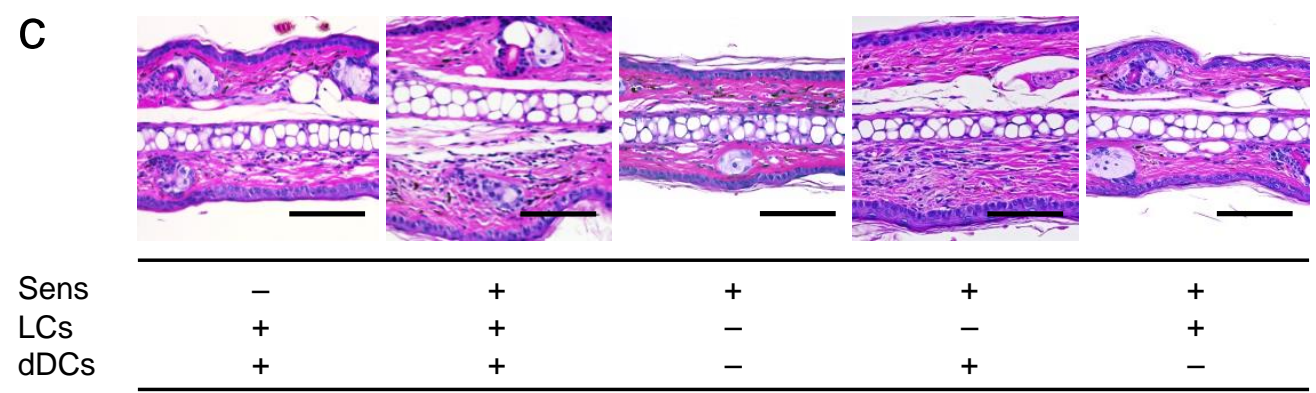

d

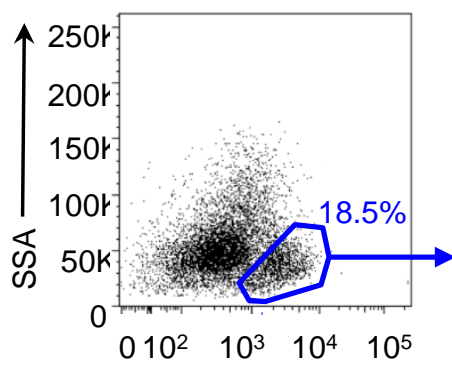

TCR beta

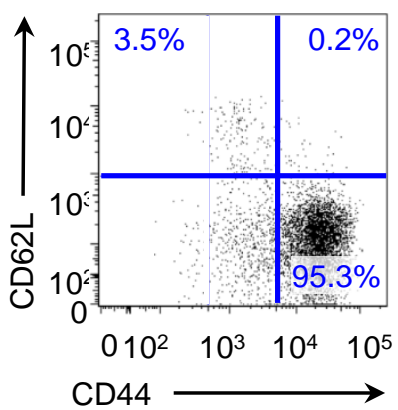




\section{Supplementary Figure 3}

a

\begin{tabular}{|c|c|c|c|}
\hline & $\begin{array}{l}\text { Number of } \\
\text { cluster } \\
\left(/ \mathrm{mm}^{2}\right)\end{array}$ & $\begin{array}{c}\text { Diameter of } \\
\text { cluster } \\
(\mu \mathrm{m})\end{array}$ \\
\hline \multirow{5}{*}{ 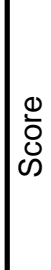 } & 0 & $0-1$ & $0-50$ \\
\hline & 1 & $2-3$ & $51-75$ \\
\hline & 2 & $4-5$ & $76-100$ \\
\hline & 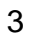 & $6-7$ & $101-125$ \\
\hline & & 8- & 126- \\
\hline
\end{tabular}

C

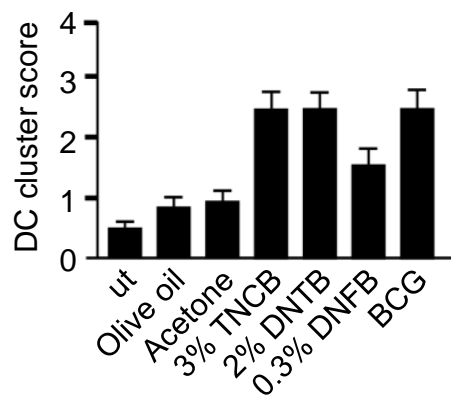

e

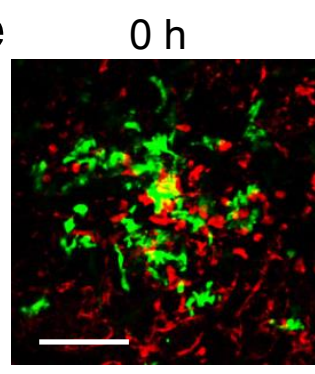

b

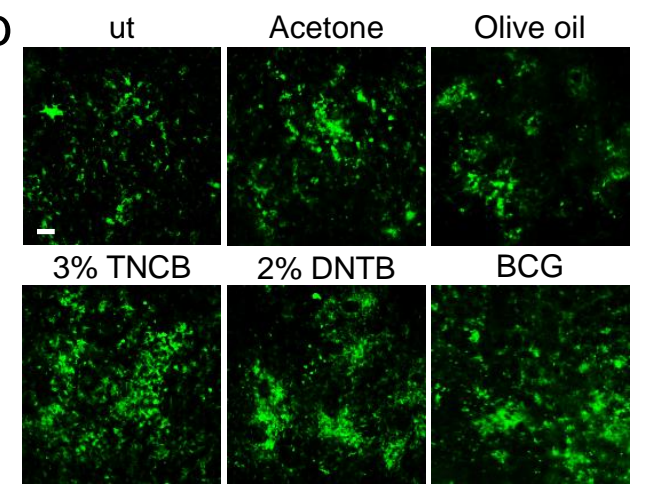

d

Back skin

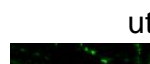

ut

$0.5 \% \mathrm{DNFB}$

Foot pad
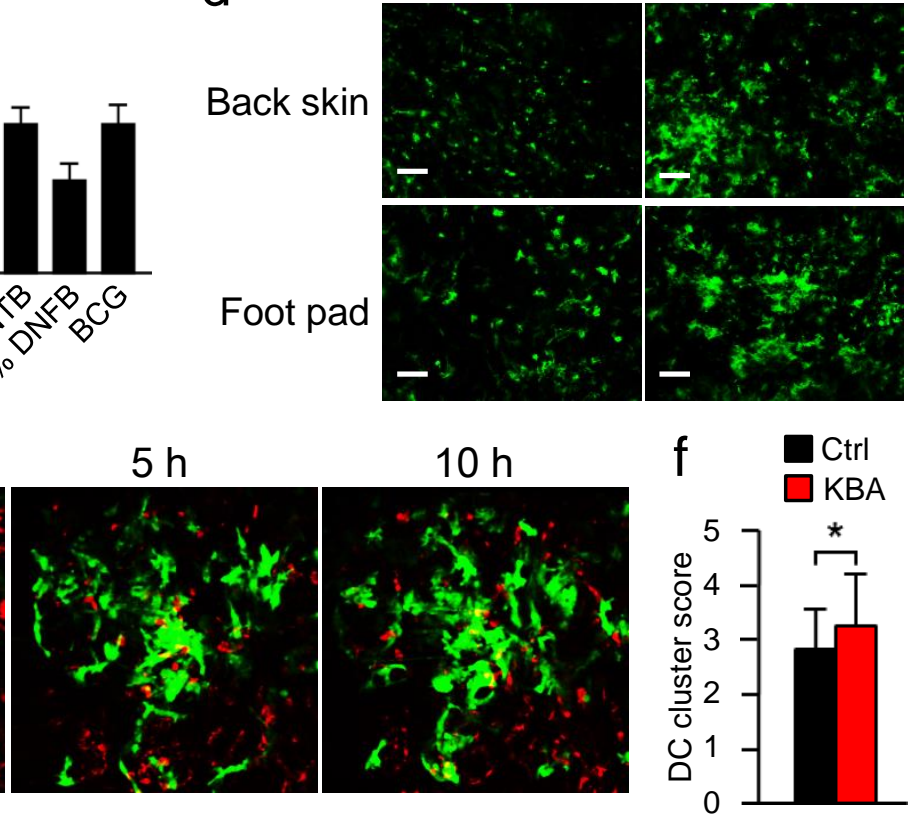


\section{Supplementary Figure 4}
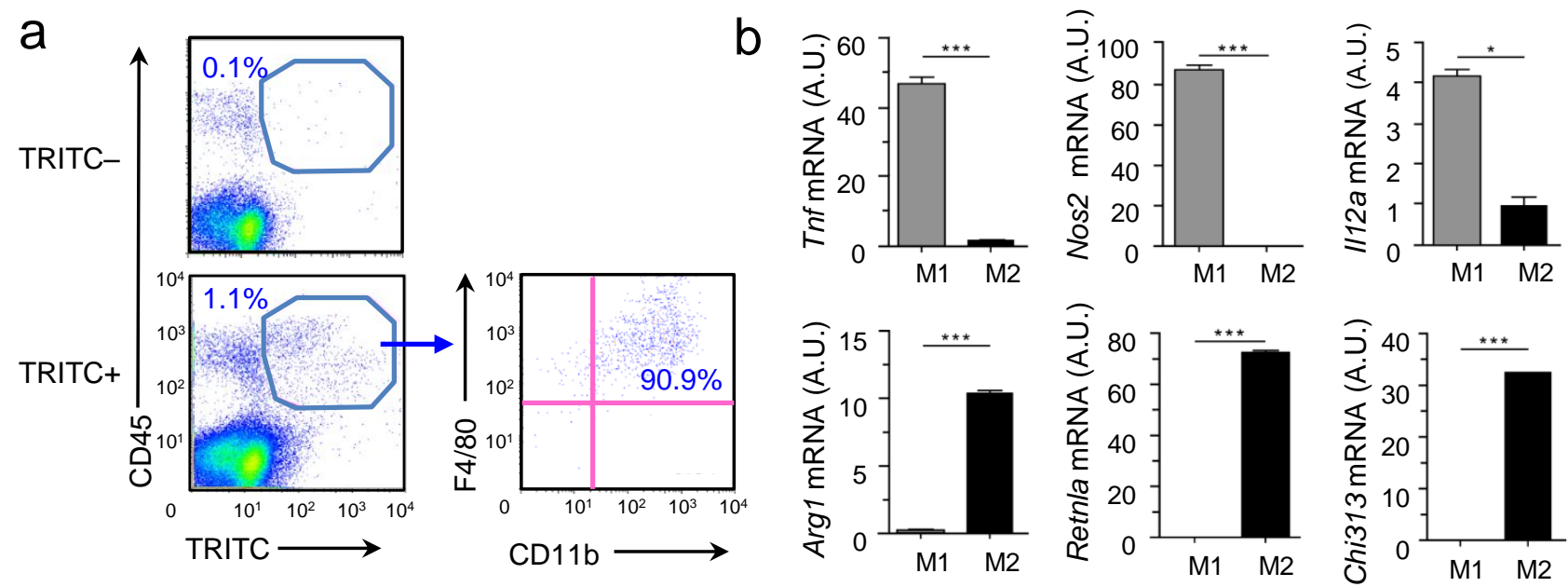


\section{Supplementary Figure 5}
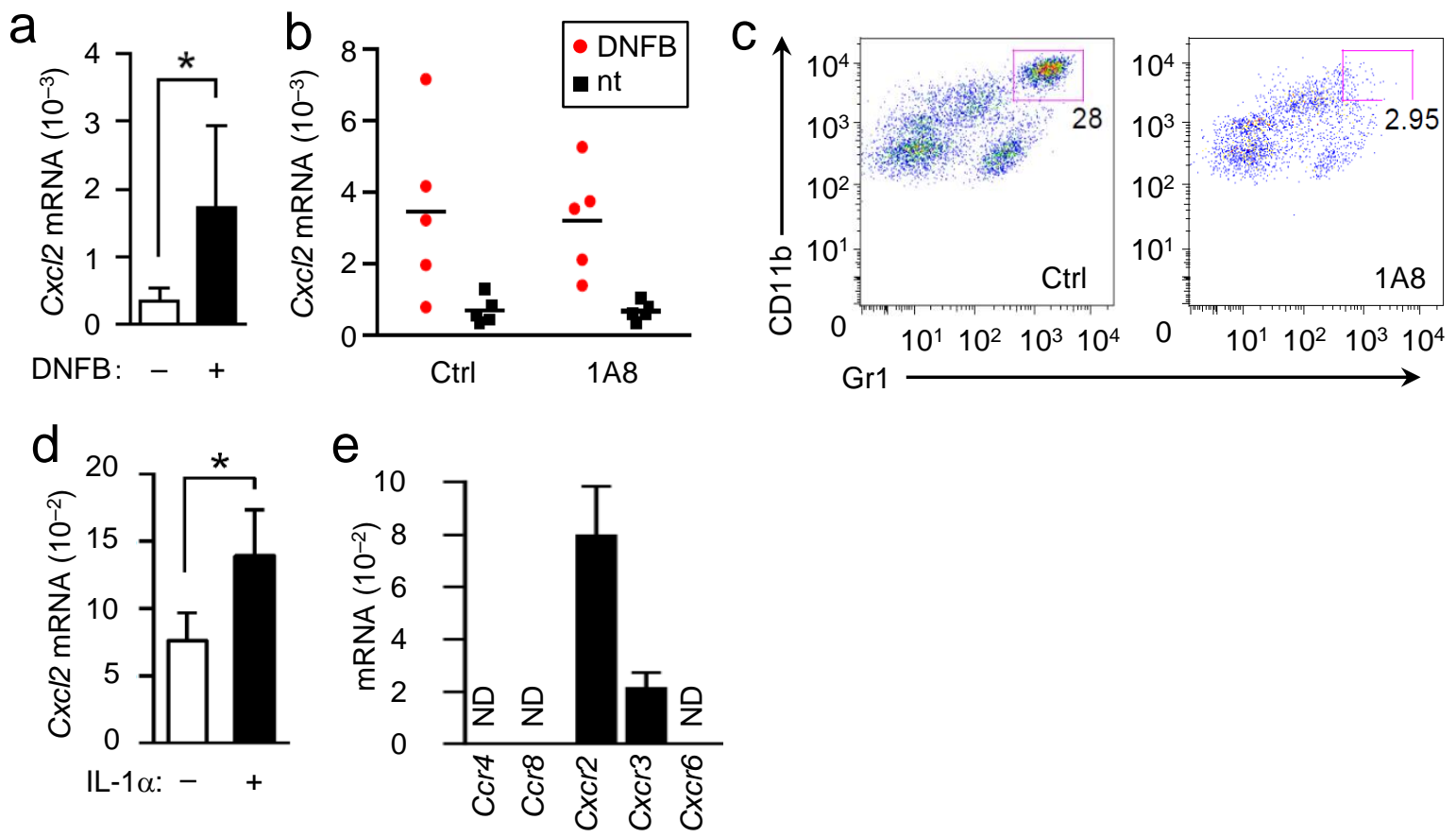
Supplementary Figure 6

a

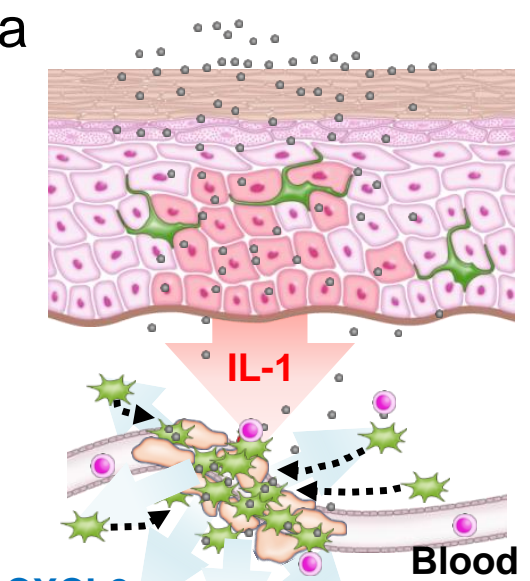

CXCL2

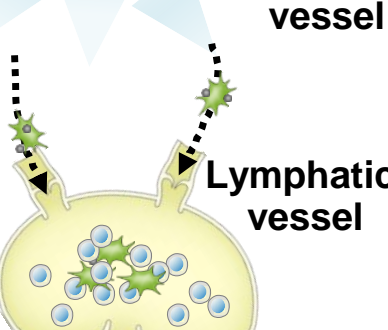

Draining

LN b
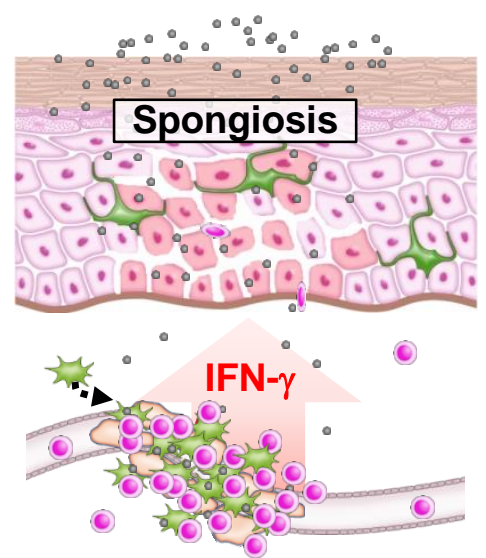

leukocyte cluster formation
$\because$ Hapten
诰 DCs
$\approx$ Macrophages
(2) Naive Tcells
- Effector Tcells 